\title{
Does zero-profile anchored cage accompanied by a higher postoperative subsidence compared with cage-plate construct? A meta-analysis
}

Yingjie Lu', Yuepeng Fang ${ }^{1}$, Xu Shen ${ }^{2}$, Dongdong Lu' ${ }^{1}$ Liyu Zhou ${ }^{1}$, Minfeng Gan ${ }^{1 *}$ and Xuesong Zhu ${ }^{1 *}$

\begin{abstract}
Background: The zero-profile anchored cage (ZP) has been widely used for its lower occurrence of dysphagia. However, it is still controversial whether it has the same stability as the cage-plate construct (CP) and increases the incidence of postoperative subsidence. We compared the rate of subsidence after anterior cervical discectomy and fusion (ACDF) with ZP and CP to determine whether the zero-profile device had a higher subsidence rate.

Methods: We performed a meta-analysis of studies that compared the subsidence rates of ZP and CP. An extensive and systematic search covered the PubMed and Embase databases according to the PRISMA guidelines and identified ten articles that satisfied our inclusion criteria. Relevant clinical and radiological data were extracted and analyzed by the RevMan 5.3 software.

Results: Ten trials involving 626 patients were included in this meta-analysis. The incidence of postoperative subsidence in the ZP group was significantly higher than that in the CP group [15.1\% (89/588) versus 8.8\% (51/581), $\mathrm{OR}=1.97(1.34,2.89), P=0.0005]$. In the subgroup analysis, we found that the definition of subsidence did not affect the higher subsidence rate in the ZP group. Considering the quantity of operative segments, there was no significant difference in the incidence of subsidence between the two groups after single-level fusion (OR 1.43, 95\% $\mathrm{Cl} 0.61-3.37, P=0.41)$. However, the subsidence rate of the ZP group was significantly higher than that of the CP group (OR 2.61, 95\% Cl 1.55-4.40, $P=0.0003$ ) after multilevel ( $\geq$ 2-level) procedures. There were no significant differences in intraoperative blood loss, JOA score, NDI score, fusion rate, or cervical alignment in the final follow-up between the two groups. In addition, the CP group had a longer operation time and a higher incidence of dysphagia than the ZP group at each follow-up time.

Conclusion: Based on the limited evidence, we suggest that ZP has a higher risk of postoperative subsidence than $\mathrm{CP}$, although with elevated swallowing discomfort. A high-quality, multicenter randomized controlled trial is required to validate our results in the future.
\end{abstract}

Keywords: Anterior fusion, Cervical degenerative disease, Zero-profile device, Subsidence, Meta-analysis

\footnotetext{
* Correspondence: zhuxs0811@139.com; zhuxs@suda.edu.com

'Department of Orthopedic Surgery, The First Affiliated Hospital of Soochow University, 899 Pinghai Road, Suzhou 215000, China

Full list of author information is available at the end of the article
}

(c) The Author(s). 2020 Open Access This article is licensed under a Creative Commons Attribution 4.0 International License, which permits use, sharing, adaptation, distribution and reproduction in any medium or format, as long as you give appropriate credit to the original author(s) and the source, provide a link to the Creative Commons licence, and indicate if changes were made. The images or other third party material in this article are included in the article's Creative Commons licence, unless indicated otherwise in a credit line to the material. If material is not included in the article's Creative Commons licence and your intended use is not permitted by statutory regulation or exceeds the permitted use, you will need to obtain permission directly from the copyright holder. To view a copy of this licence, visit http://creativecommons.org/licenses/by/4.0/ The Creative Commons Public Domain Dedication waiver (http://creativecommons.org/publicdomain/zero/1.0/) applies to the data made available in this article, unless otherwise stated in a credit line to the data. 


\section{Introduction}

Anterior cervical discectomy and fusion (ACDF) is the standard surgical procedure for cervical degenerative disk disease (CDDD) [1]. The use of the anterior plate can increase the stability of the cervical spine and promote early intervertebral fusion after surgery, and it is widely used in clinical practice [2-4]. However, studies over the past decade have shown that the use of anterior plates can increase the incidence of postoperative dysphagia, and even cause long-term unremitting swallowing discomfort [5-8]. To solve this complication, many researchers have adopted a variety of new self-locking zero-profile anchored cages (ZPs), such as the Zero-P, $\mathrm{MC+}$, and ROI-C [9-13]. These types of devices can reduce the compression of prevertebral soft tissue, and have similar stability and clinical efficacy as traditional cage-plate constructs [14-16]. Additionally, the new devices are easy to place and can reduce the operation time and blood loss significantly $[10,13]$, so their clinical application has gradually increased in recent years.

However, some studies have found that these ZPs are prone to subsidence because they do not have a strong fixation ability to maintain the height of the intervertebral space $[9,11]$. This may lead to narrowing of the foramen, reducing of cervical lordosis, and neurological symptoms, affecting the long-term efficacy of patients [17-20]. At present, there is no consistent conclusion about whether the ZP has a higher subsidence rate than the traditional cage-plate construct $(\mathrm{CP})$ in the literature.

Therefore, we reviewed the literature and conducted this meta-analysis to compare the postoperative subsidence and other clinical outcomes of ACDF with the ZP and $\mathrm{CP}$; we aimed to determine whether the $\mathrm{ZP}$ has a higher postoperative subsidence rate and similar clinical efficacy as the CP.

\section{Materials and methods Search strategy}

Our research complied with the guidelines of Preferred Reporting Items for Systematic Reviews and Meta-Analysis (PRISMA) [21, 22]. The electronic PubMed and Embase databases were searched from January 01, 2010 until April 30, 2019. The search was conducted with the following search strategy: "zeroprofile[Title]" OR "Zero-P[Title]" OR "self-locking[Title]" OR "anchored spacer[Title]" OR "stand-alone cage[Title]" AND "cervical[Title]". According to the selection methods and the inclusion criteria, the relevant articles and their references were reviewed.

\section{Selection criteria}

All systematic reviews and meta-analysis on clinical controlled trials for CDDD were reviewed. The inclusion criteria for studies in this research were as follows: (1) patients had a failure of at least 6 months of nonoperative treatments for CDDD; (2) the studies included a comparison of patients who accepted a ZP with those who received a CP; (3) the studies analyzed and compared the radiological outcomes of subsidence; (4) the studies involved an evaluation of an index of clinical effects: Japanese Orthopaedic Association (JOA) score, Neck Disability Index (NDI) score, operative time, intraoperative blood loss, fusion rate, cervical alignment, and complications; and (5) there was a follow-up period of more than 12 months.

We excluded studies that were not in line with clinical controlled studies, such as case reports, meta-analysis, conference abstracts, reviews, commentaries, and letters to the editor. In addition, we only included English language articles in this study.

\section{Data extraction}

Articles from the literature were thoroughly searched and reviewed from by two reviewers (YJL and YPF) individually and repeatedly. Any discord was resolved through consultation with a third reviewer (XSZ). The data extracted from the article text, tables, and graphs of the qualified studies. The primary radiological data included subsidence, fusion rate, and cervical alignment, and the primary clinical data included JOA, NDI, operative time, blood loss, and the rate of dysphagia. The other basic data included study design, sample size, characteristics of patients, follow-up duration, and type of implants. If partial information from a study was missing, the corresponding author was contacted for the missing data.

\section{Statistical analysis}

Data analysis was completed by using the Review Manager Software (RevMan 5.3, the Cochrane Collaboration). The continuous variables (operative time, blood loss, JOA, NDI, and cervical alignment) were evaluated by weighted mean difference (WMD), while dichotomous variables (incidence of subsidence, fusion rate, and dysphagia) were evaluated by odds ratio (OR). Considering the different definitions of subsidence $(\geq 2$ $\mathrm{mm}$ or $\geq 3 \mathrm{~mm}$ ) and quantity of operative segments (1level or $\geq 2$-level) used in the different studies, we performed corresponding subgroup analysis upon incidence of subsidence. The $I^{2}$ statistic was used to reflect the degree of heterogeneity. An $I^{2}$ statistic $>50 \%$ identified obvious heterogeneity, and random-effects models were performed in these instances. If the $I^{2}$ statistic was $\leq 50 \%$ (low heterogeneity), fixed-effects models were used. The study also used a funnel plot to evaluate publication bias for subsidence. A $P$ value of 0.05 or less was considered statistically significant. 


\section{Results}

Literature search and study characteristics

A total of 221 related records were obtained by searching the databases above. After removing 26 duplicated studies and 22 non-English language articles, 173 studies remained for screening and 163 records were excluded according to the selection criteria. As a result, ten controlled trials [2, 9-13, 23-26] were included in this meta-analysis. The literature search procedure is shown in Fig. 1. All clinical trials came from different research centers. The study data and baseline characteristics of both treatment groups are presented in Table 1 .

\section{Patient demographics}

The 10 studies enrolled a total of 626 patients (315 in the ZP group and 311 in the CP group), which included 380 males and 236 females. The ZPs used in the studies included the Zero-P (Synthes GmbH, Oberdorf, Switzerland), ROI-C, ROI-MC+ (LDR, Troyes, France), PREVAIL (Medronic Sofamor Danek, Memphis, TN, USA), and the Fidji cervical cage (Abbott Spine, Bordeaux, France). The control group was treated with an anterior plating system and bone graft materials. The mean age, sex, follow-up durations, surgical levels, and other patient information from each study are listed in Table 1.

\section{Operative data}

Seven studies consisting of 447 patients (ZP group, 221; $\mathrm{CP}$ group, 226) noted the operation time $[9,11-13,23$, $25,26]$. The mean operation time was greater for the $\mathrm{CP}$ group in six studies, and after meta-analysis, the operation time was significantly greater in the $\mathrm{CP}$ group than in the ZP group (WMD - 15.87, 95\% CI - 30.62 to 1.11, $P=0.04$ ) (Fig. 2).

For the outcome regarding intraoperative blood loss, seven studies including 447 patients (ZP group, 221; CP group, 226) reported this variable [9, 11-13, 23, 25, 26]. The ZP group was noted to have lower blood loss in six studies. Overall, the $\mathrm{CP}$ group had a comparable amount of blood loss versus the ZP group (WMD - 5.51, 95\% CI - 11.69 to $0.67, P=0.08$ ) (Fig. 3).

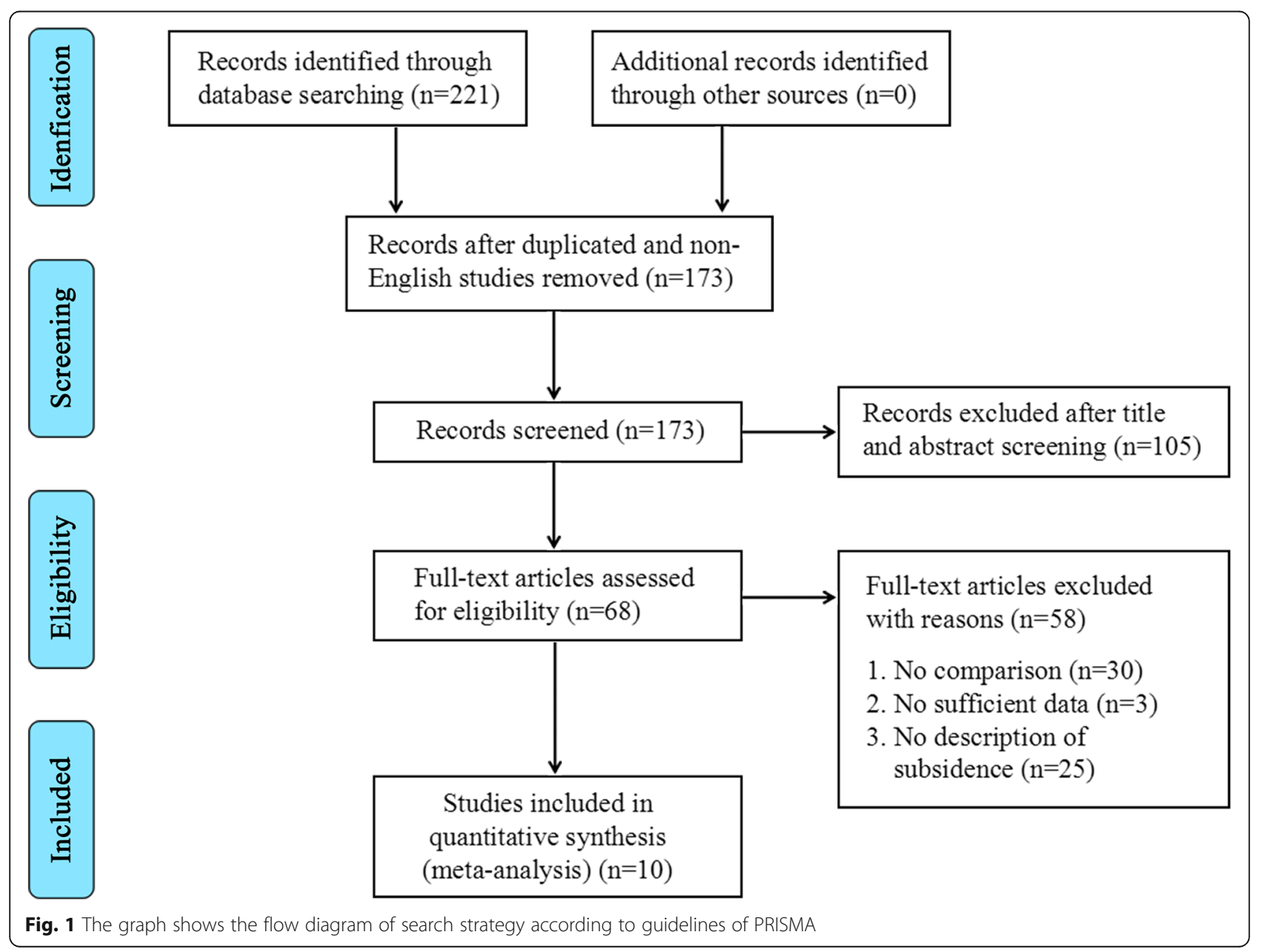




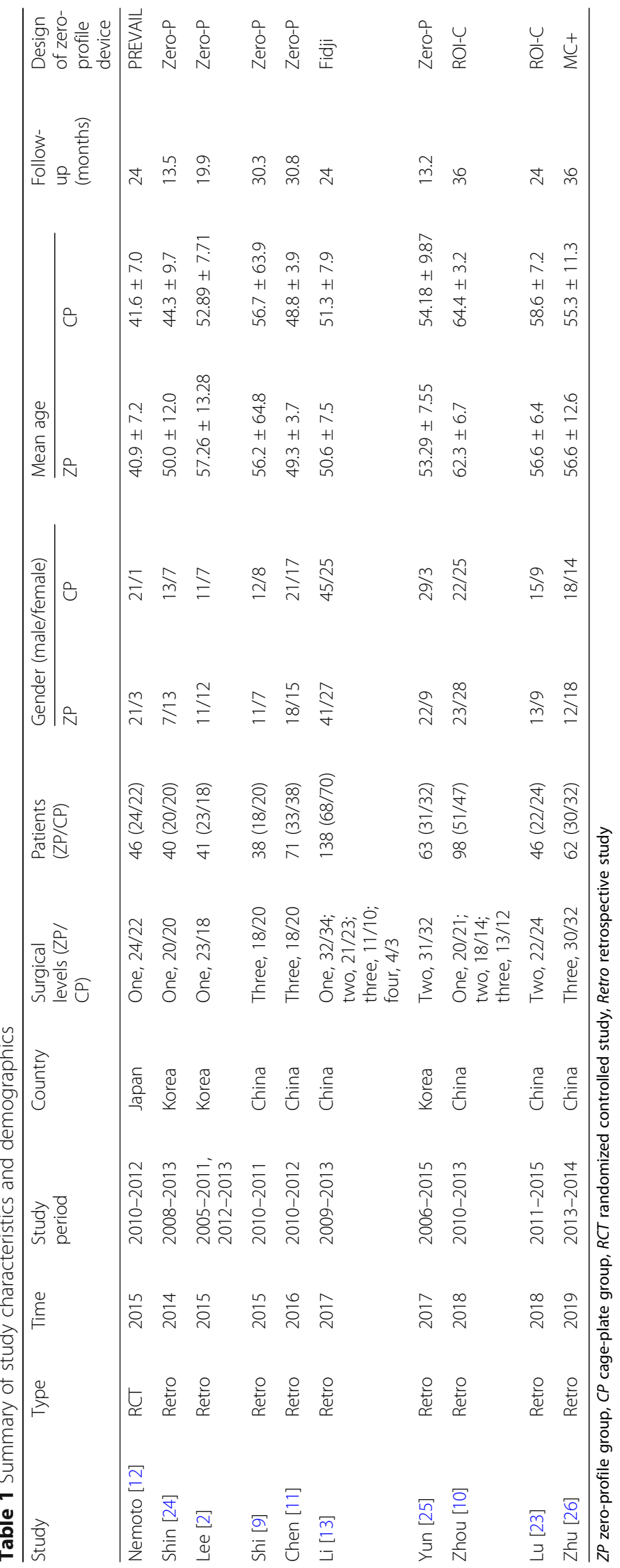




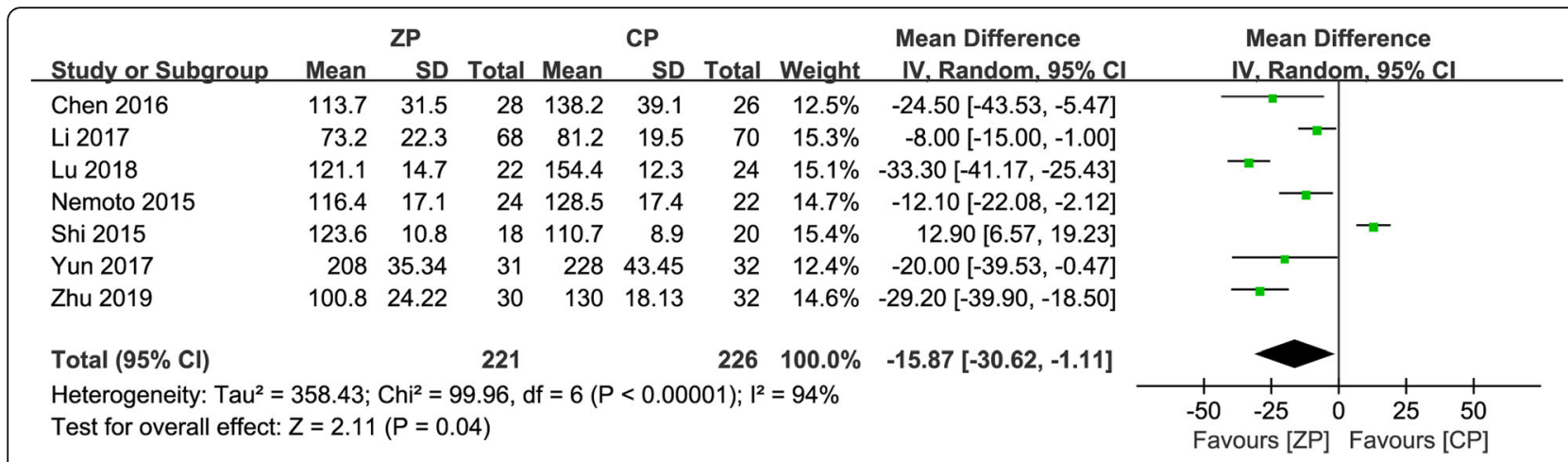

Fig. 2 The forest plot shows operation time of anterior cervical discectomy and fusion by using zero-profile anchored cage versus cage-plate construct

\section{Clinical evaluation}

Data regarding JOA and NDI scores postoperatively were documented in six studies consisting of 436 patients (ZP group, 217; CP group, 219) [9-11, 13, 23, 26]. The mean difference in JOA scores at the final follow-up between the $\mathrm{ZP}$ and $\mathrm{CP}$ groups was not significant (WMD 0.07, 95\% CI -0.12 to $0.25, P=0.48$ ). In addition, pooled NDI score data at the final follow-up did not reveal a significant difference between the two groups (WMD $-0.16,95 \% \mathrm{CI}-0.47$ to $0.16, P=0.33$ ). Figures 4 and 5 describe the above information in forest plots.

\section{Radiological assessment}

The results of radiographic fusion were described in nine studies [2, 9-13, 23, 25, 26], with fusion rates varying from 71 to $100 \%$. Successful bone union was achieved in $348 / 377$ patients $(92.3 \%)$ in the ZP group, and 359/379 patients (94.7\%) in the CP group. The forest plot analysis showed no significant difference between the two groups (OR 0.66, 95\% CI 0.36 to $1.20, P=0.17$ ) (Fig. 6).

There was a significant difference regarding cervical alignment 3 months postoperatively between the ZP and CP groups (WMD $-0.53,95 \% \mathrm{CI}-0.98$ to $-0.09, P=$
0.02). Nevertheless, the mean difference in cervical alignment between the two groups at the final follow-up was not significant (WMD $-0.75,95 \% \mathrm{CI}-1.76$ to $0.25, P=$ $0.14)$. The corresponding forest plot analysis is shown in Fig. 7.

\section{Dysphagia}

The incidence of dysphagia was reported in seven studies $[9-13,23,26]$, with results of $2.0-57.1 \%$ in the ZP group and $10.6-73.1 \%$ in the $\mathrm{CP}$ group at the early period, respectively. In the early postoperative period $(<$ 1 month), the rate of dysphagia was noted to be lower in the ZP group (OR 0.39, 95\% CI 0.24 to $0.64, P=0.0002$ ). In addition, the ZP group also had a lower incidence of dysphagia at 3 months postoperatively (OR 0.17, 95\% CI 0.06 to $0.48, P=0.0008$ ) and at the final follow-up (OR $0.11,95 \%$ CI 0.01 to $0.91, P=0.04$ ). Forest plots for the postoperative and final follow-up dysphagia evaluations are presented in Fig. 8.

\section{Subsidence}

A total of ten studies were included in the comparison of the incidence of subsidence between the $\mathrm{ZP}$ and $\mathrm{CP}$ groups $[2,9-13,23-26]$. The subsidence rates were

\begin{tabular}{|c|c|c|c|c|c|c|c|c|c|}
\hline \multirow[b]{2}{*}{ Study or Subgroup } & \multicolumn{3}{|c|}{ ZP } & \multicolumn{2}{|r|}{$\mathrm{CP}$} & \multirow[b]{2}{*}{ Total } & \multirow[b]{2}{*}{ Weight } & \multirow{2}{*}{$\begin{array}{l}\text { Mean Difference } \\
\text { IV, Random, } 95 \% \mathrm{Cl}\end{array}$} & \multirow{2}{*}{$\begin{array}{c}\text { Mean Difference } \\
\text { IV, Random, } 95 \% \text { CI }\end{array}$} \\
\hline & Mean & SD & Total & Mean & SD & & & & \\
\hline Chen 2016 & 159.9 & 38.1 & 28 & 187.4 & 42.8 & 26 & $6.3 \%$ & $-27.50[-49.17,-5.83]$ & \\
\hline Li 2017 & 54.6 & 33.3 & 68 & 75.7 & 46.8 & 70 & $11.9 \%$ & $-21.10[-34.62,-7.58]$ & \\
\hline Lu 2018 & 79.1 & 12 & 22 & 86.3 & 15.8 & 24 & $18.8 \%$ & $-7.20[-15.27,0.87]$ & - \\
\hline Nemoto 2015 & 27.7 & 19 & 24 & 30.1 & 25.8 & 22 & $12.3 \%$ & $-2.40[-15.59,10.79]$ & \\
\hline Shi 2015 & 103.9 & 8.8 & 18 & 104.6 & 6.9 & 20 & $23.3 \%$ & $-0.70[-5.77,4.37]$ & \\
\hline Yun 2017 & 221.61 & 61.21 & 31 & 204.68 & 46.41 & 32 & $4.4 \%$ & $16.93[-9.96,43.82]$ & \\
\hline Zhu 2019 & 29.6 & 9.82 & 30 & 30.5 & 11.63 & 32 & $22.9 \%$ & $-0.90[-6.25,4.45]$ & \\
\hline Total $(95 \% \mathrm{Cl})$ & & & 221 & & & 226 & $100.0 \%$ & $-5.51[-11.69,0.67]$ & \\
\hline $\begin{array}{l}\text { Heterogeneity: } \mathrm{Tau}^{2}= \\
\text { Test for overall effect: }\end{array}$ & $\begin{array}{l}35.94 ; \mathrm{Cr} \\
Z=1.75\end{array}$ & $\begin{array}{l}h i^{2}=16 \\
(P=0.08\end{array}$ & $\begin{array}{l}\text { 32, } \mathrm{df}= \\
8)\end{array}$ & $=6(P=0$ & $0.01) ;\left.\right|^{2}$ & $=63 \%$ & & & \begin{tabular}{ccccc}
1 & 1 & 1 & 1 & 1 \\
-50 & -25 & 0 & 25 & 50 \\
\multicolumn{3}{l}{ Favours [ZP] } & Favours [CP]
\end{tabular} \\
\hline
\end{tabular}




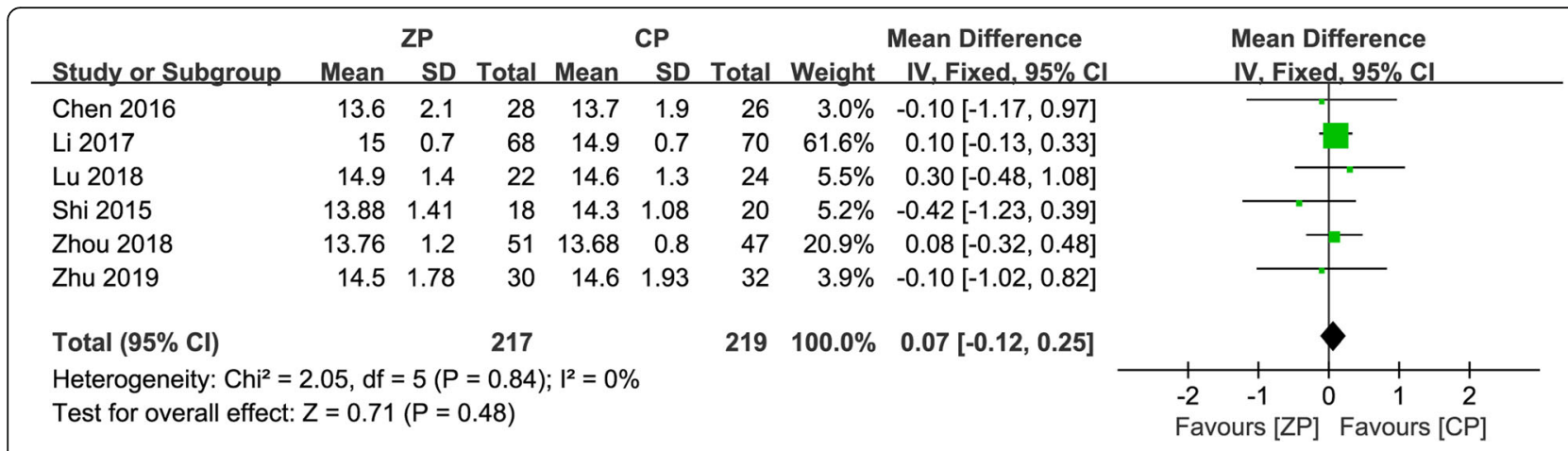

Fig. 4 The forest plot shows JOA score of anterior cervical discectomy and fusion by using zero-profile anchored cage versus cage-plate construct at final follow-up

$15.1 \%(89 / 588)$ in the ZP group and $8.8 \%(51 / 581)$ in the $\mathrm{CP}$ group. The subsidence rate was significantly higher in the ZP group patients (OR 1.97, $95 \%$ CI 1.34 to 2.89 , $P=0.0005)$. The forest plot analysis of subsidence and the funnel plot evaluation of publication bias are presented in Figs. 9 and 10, respectively.

We performed a subgroup analysis stratified by the definition of subsidence, which included subsidence $\geq 2$ $\mathrm{mm}$ in five studies $[2,9,12,13,25]$ and $\geq 3 \mathrm{~mm}$ in four studies $[10,11,23,24]$. In the ZP group, the incidence was $16.5 \%(42 / 255)$ and $12.3 \%(30 / 243)$ with the definition of $\geq 2 \mathrm{~mm}$ and $\geq 3 \mathrm{~mm}$, respectively. Correspondingly, it was $10.2 \%(26 / 254)$ and $7.4 \%(17 / 231)$ in the CP group. These results showed that there was a higher risk of subsidence in the ZP group, regardless of whether the definition of subsidence was $\geq 2 \mathrm{~mm}$ (OR 1.78, 95\% CI 1.03 to $3.06, P=0.04)$ and $\geq 3 \mathrm{~mm}$ (OR $1.98,95 \% \mathrm{CI}$ 1.00 to $3.91, P=0.05$ ).

A subgroup analysis stratified by the quantity of operative segments was also performed, which included single-level surgery in three studies $[2,12,24]$ and multilevel surgery in five studies $[9,11,23,25,26]$. In the single-segment operations, the incidence of subsidence between the ZP and $\mathrm{CP}$ groups was not significant (OR
1.43, 95\% CI 0.61 to $3.37, P=0.41$ ). For the multilevel surgeries, the ZP group had a higher incidence of subsidence (OR 2.61, 95\% CI 1.55 to $4.40, P=0.0003$ ). The forest plots for the subgroup analysis of subsidence are described in Figs. 11 and 12, respectively.

\section{Discussion}

ACDF is a classic procedure in treating cervical degenerative diseases that can remove the prominent disk and osteophyte and relieve compressions of the spinal cord and nerve root. It is effective and widely used in the treatment of patients with CDDD [1]. The anterior plating system not only stabilizes the upper and lower vertebral bodies, but also improves the rate of intervertebral fusion and avoids the risk of pseudarthrosis [3, 4]. Furthermore, it can maintain the cervical sagittal alignment and prevent graft extrusion or subsidence [2].

However, the application of the anterior plate has a high incidence of postoperative dysphagia [5-8]. In response to this problem, various stand-alone anchored spacers have been designed for clinical treatment. Wang et al. [8] found that the dysphagia rate was only $4.5 \%$ after one-level ACDF with a Zero-P device, which was significantly lower than $32 \%$ dysphagia rate reported

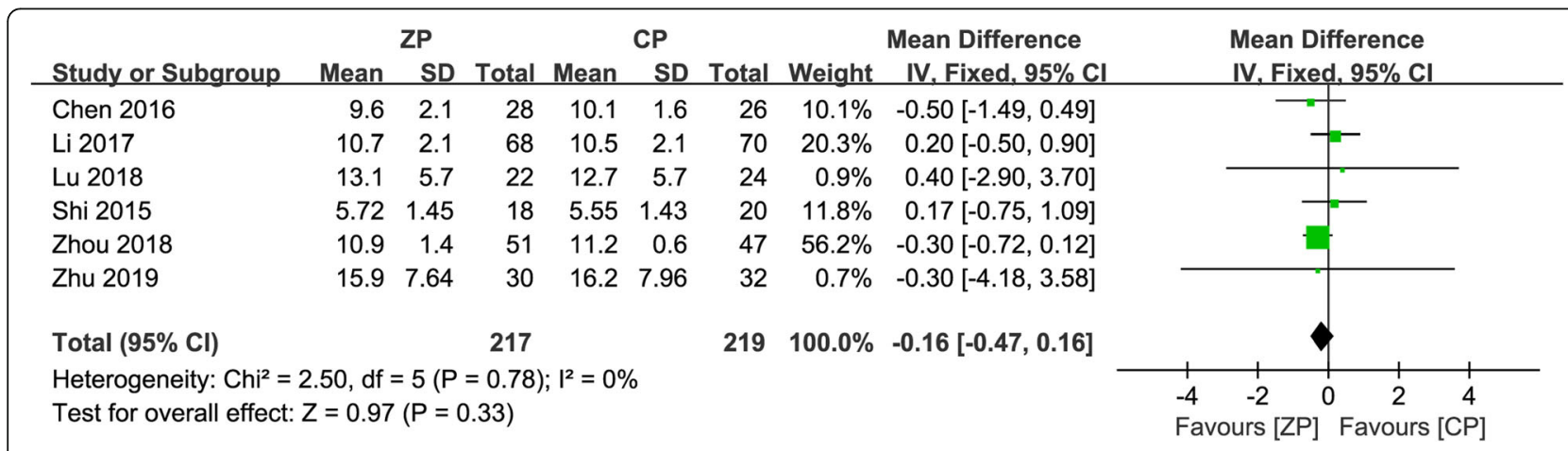

Fig. 5 The forest plot shows NDI score of anterior cervical discectomy and fusion by using zero-profile anchored cage versus cage-plate construct at final follow-up 


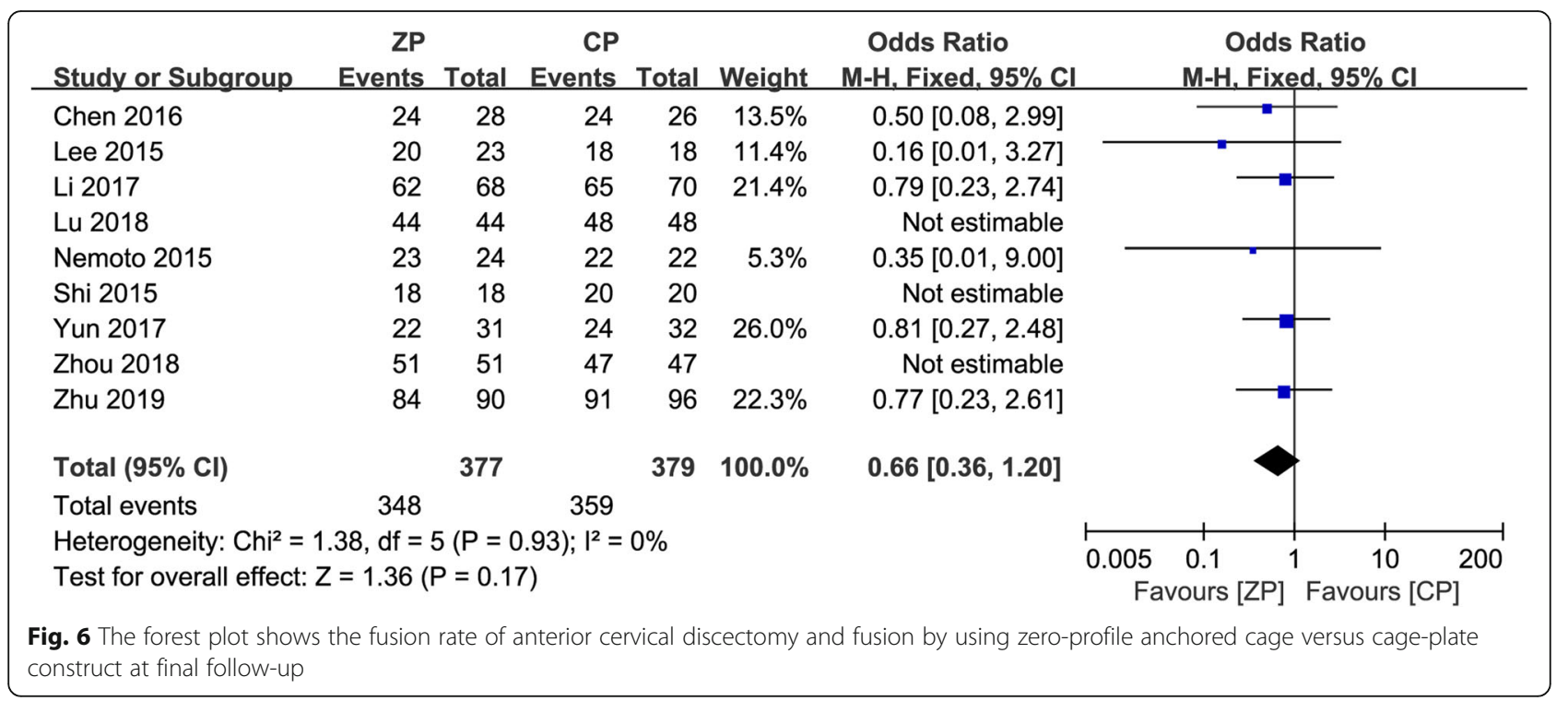

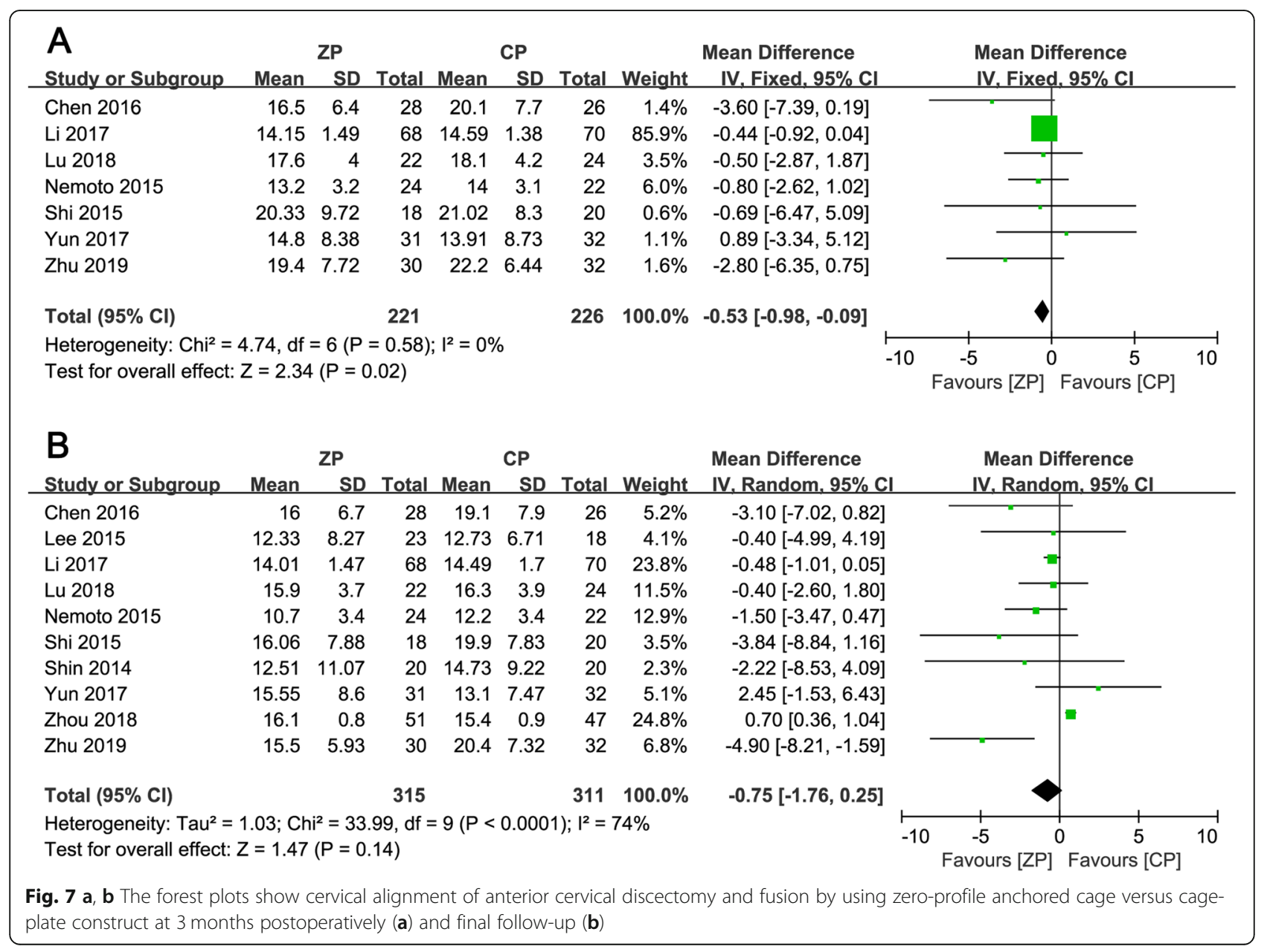




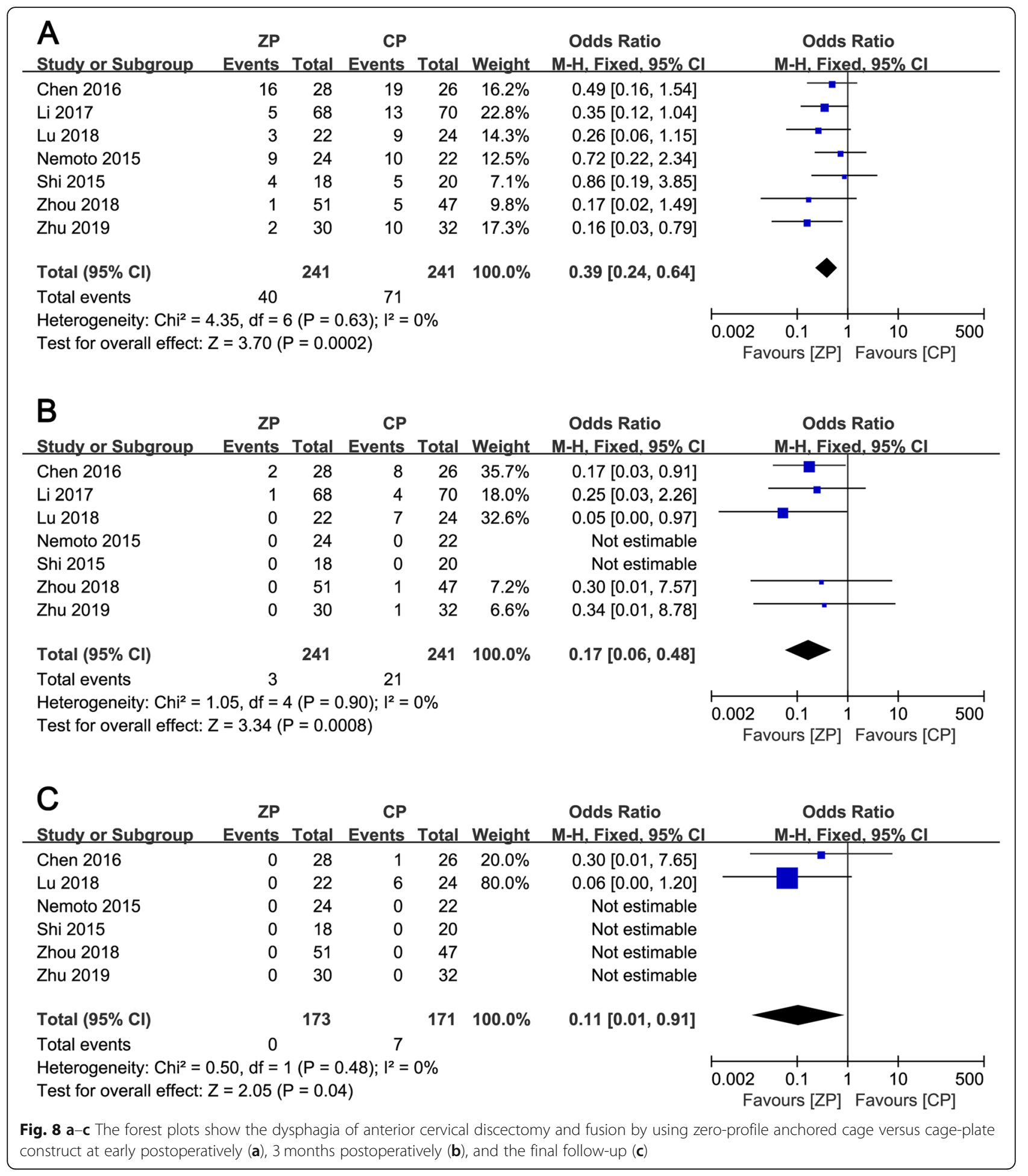

when using the cage-plate construct. Yang et al. [5] reported that the Zero-P device has a lower incidence of dysphagia than the anterior plating system after multilevel fusion $(4.3 \%$ versus $25 \%, P=0.04)$. Hofstetter et al. [7] also found that the use of zero-profile anchored spacers $(\mathrm{MC}+$ or $\mathrm{ROI}-\mathrm{C})$ had significantly lower rates of dysphagia than conventional plate instruments after surgery $(2.9 \%$ versus $20 \%, P=0.027)$.

Subsidence is another equally important adverse event after ACDF. It usually refers to an object with a greater elastic modulus (e.g., cage or spacer) entering another object of relatively lower elastic modulus (e.g., vertebral 


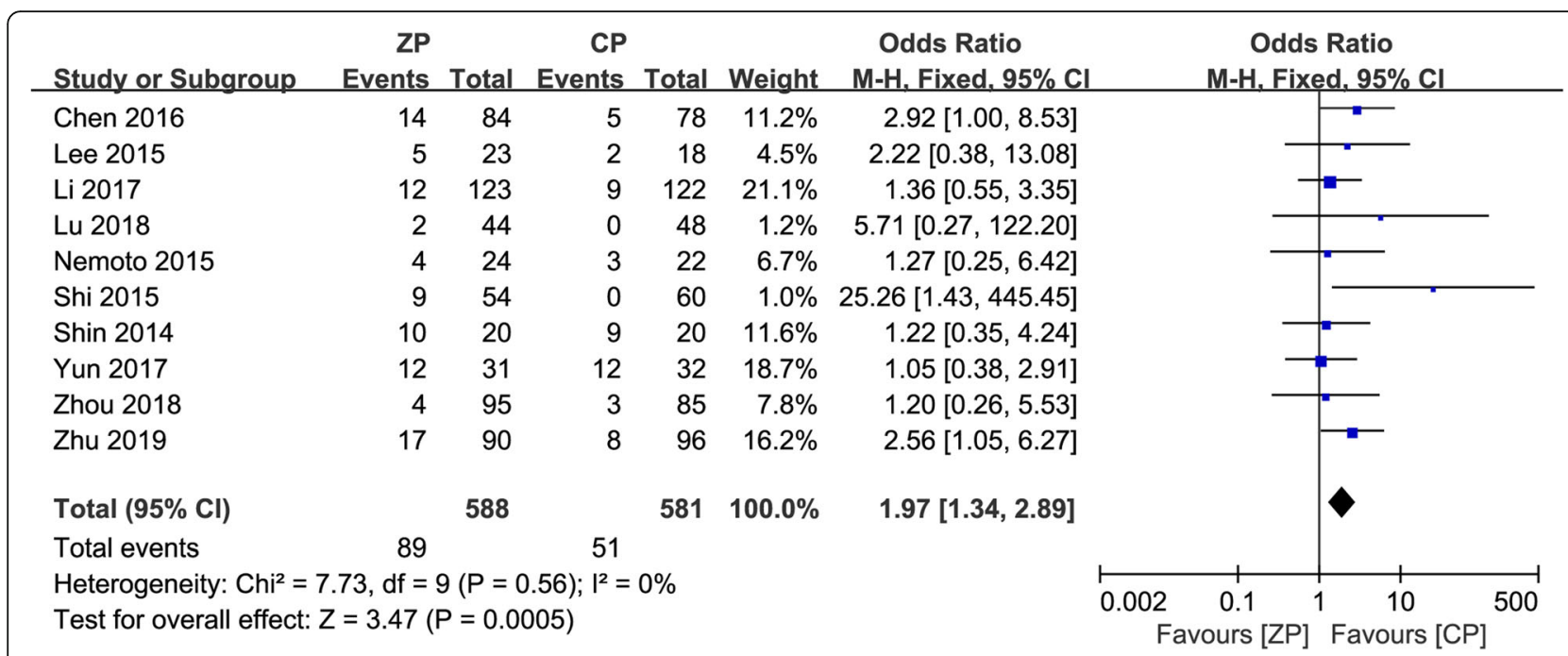

Fig. 9 The forest plot shows subsidence of anterior cervical discectomy and fusion by using zero-profile anchored cage versus cage-plate construct at the final follow-up

body). The subsidence of the cage causes the loss of intervertebral disk height, which can result in narrowing of the foramen, nerve root compression, and pseudoarthrosis due to cervical instability [27]. Eventually, the cervical spine loses physiological curvature, resulting in kyphosis. This means that segmental subsidence arouses significant morbidity during the postoperative period [18].

A systematic review of seventy-one studies reported that the mean incidence of cage subsidence after ACDF was $21 \%$ (ranging from 0 to $83 \%$ ) [27]. Many studies have reported that the use of plates can reduce the incidence of subsidence after ACDF. Lee et al. [18] confirmed that the nonuse of plates was a risk factor for subsidence and had a significantly high subsidence rate after single-level ACDF (40\% versus $12.5 \%, P=0.025$ ). Kim et al. [28] found that the postoperative subsidence rate of patients using a stand-alone cage was higher than that of patients using a cage-plate construct after twolevel fusion $(66.6 \%$ versus $30 \%, P=0.049)$, which indicated that the use of a plate could maintain the height of the intervertebral disk and play a pivotal role in reducing postoperative subsidence. However, the incidence of subsidence for ZP compared to $\mathrm{CP}$ after reviewing the literature is not clear. Therefore, we conducted this meta-analysis to determine whether there is a statistically high risk of cage subsidence after ACDF with ZP.

Ten trials including 10 cohorts with a total of $626 \mathrm{pa}-$ tients were included in this study. There were no significant differences in blood loss, JOA score, NDI score,

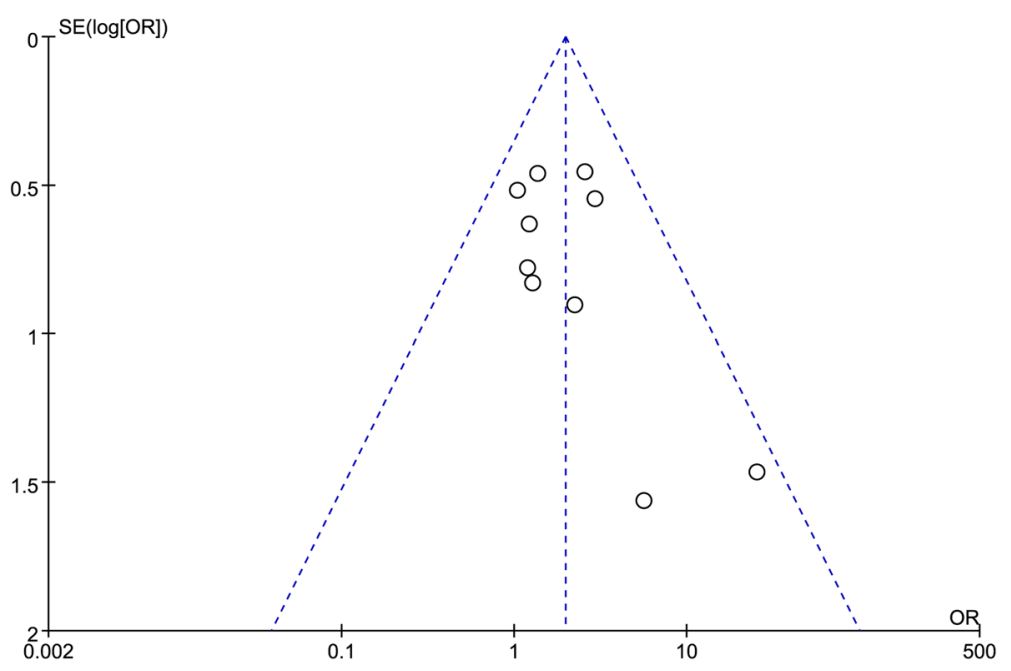

Fig. $10 \mathrm{~A}$ funnel plot for publication bias of subsidence at the final follow-up 


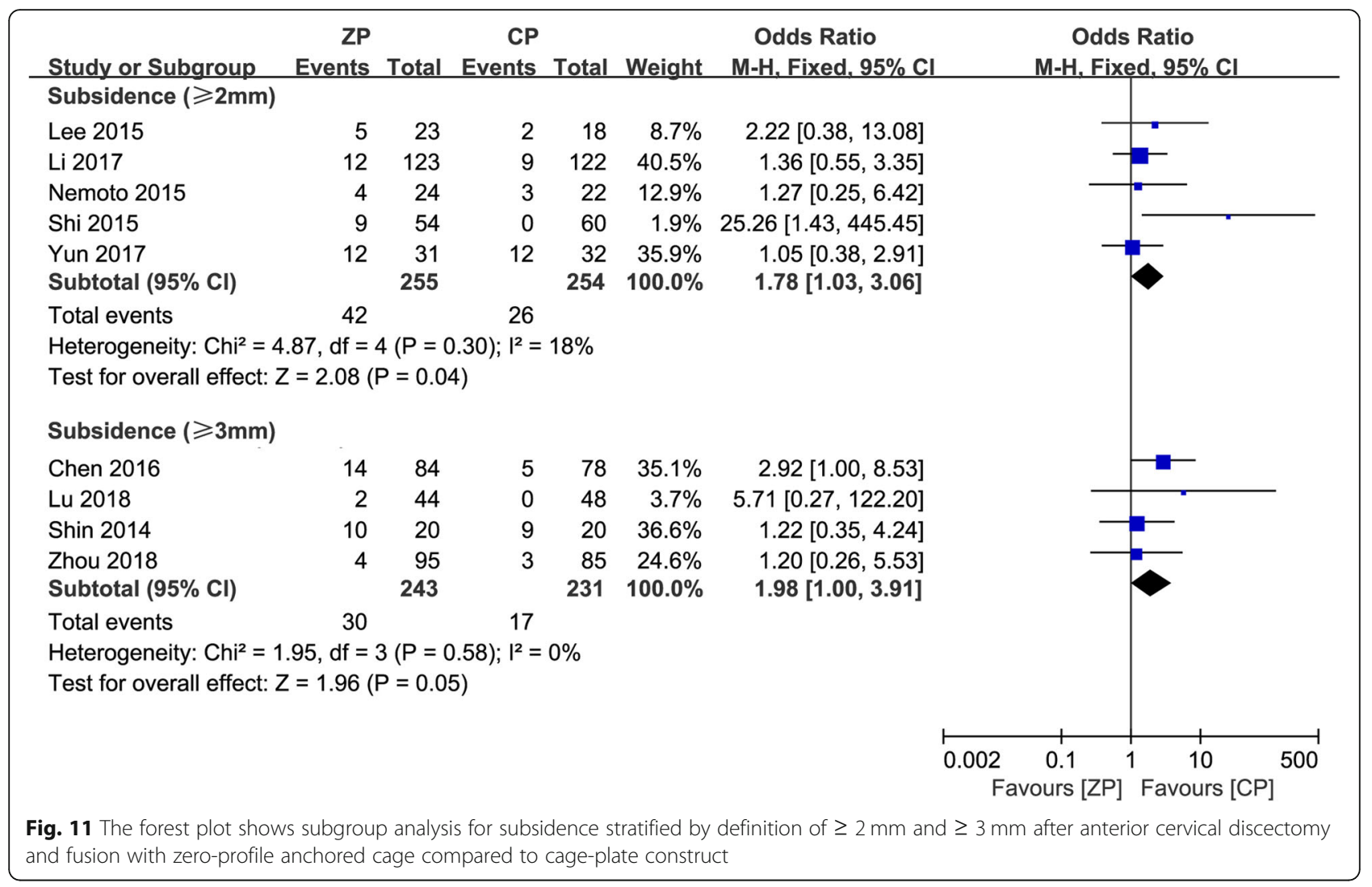

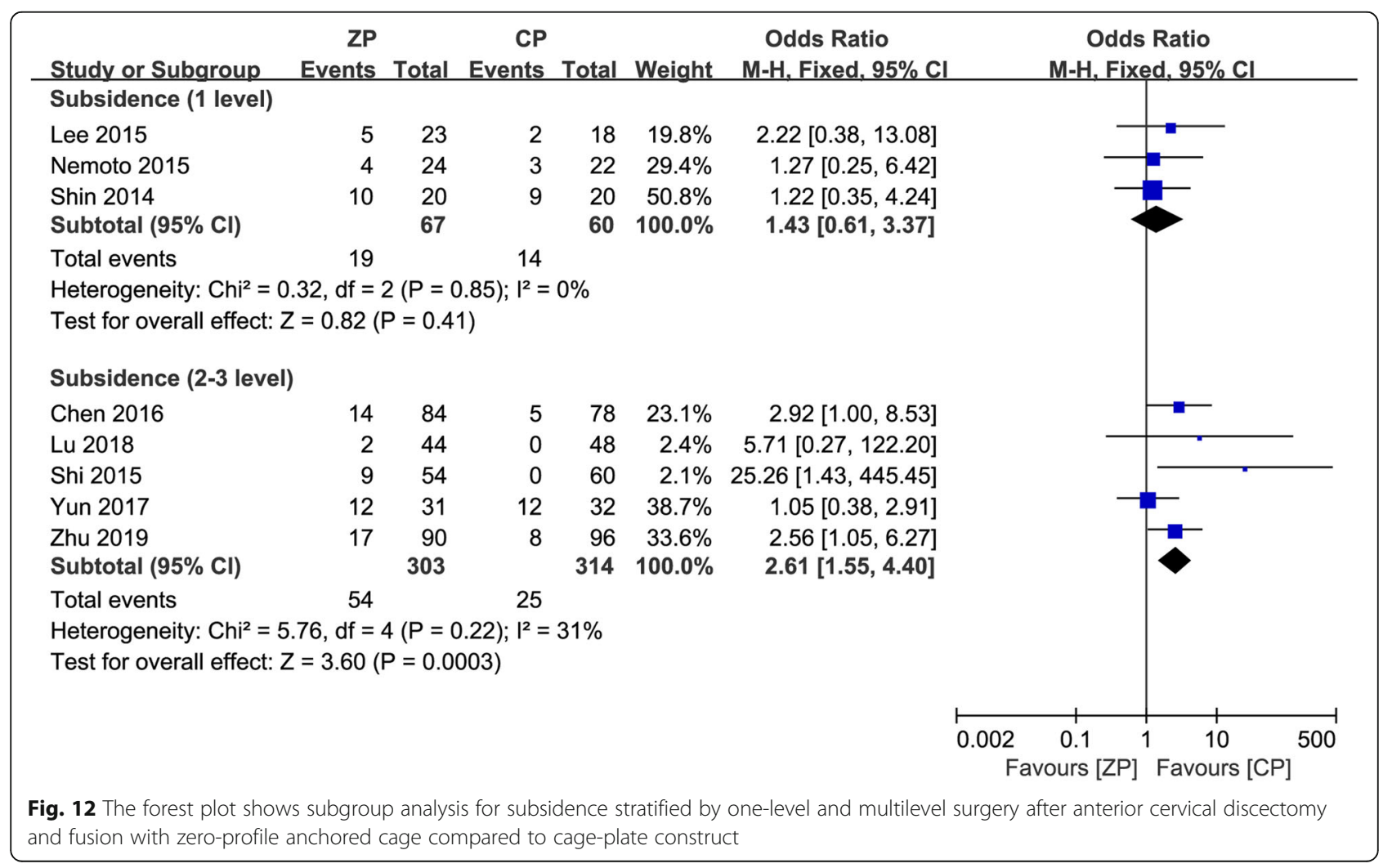


fusion rate, or cervical alignment at the final follow-up between the two devices by meta-analysis. Additionally, we found that the incidence of dysphagia in the $\mathrm{CP}$ group was significantly higher than that in the ZP group at each follow-up time, which was consistent with previous studies. Xiao et al. [29] conducted a meta-analysis that included 1066 patients to compare the postoperative dysphagia rate between zero-profile anchored spacers and cage-plate constructs after ACDF. Their study found that the ZP group had a significantly lower risk of dysphagia. Nambiar et al. [30] and Tong et al. [31] also found that the ZP group achieved a lower incidence of dysphagia after single-level and multilevel fusion, respectively.

The results of this study suggested that the ZP group was associated with a high incidence of subsidence, when compared with the $\mathrm{CP}$ group. Considering the different definitions of subsidence used in the above ten studies, we conducted subgroup analysis of subsidence defined as $\geq 2 \mathrm{~mm}$ and subsidence defined as $\geq 3 \mathrm{~mm}$. However, we found that the incidence of subsidence in the $\mathrm{ZP}$ group was still higher than that in the $\mathrm{CP}$ group, regardless of definition. Therefore, it could be considered that different definitions of subsidence did not affect the consequences. Then, we performed subgroup analysis according to the quantity of operative segments. There was no significant difference in the rate of subsidence between the ZP group and CP group after singlesegment ACDF, while the subsidence rate of the $\mathrm{ZP}$ group was significantly higher than that of the $\mathrm{CP}$ group after multisegment ACDF. Therefore, we believed that there was no significant difference in the occurrence of cage subsidence after single-level ACDF with ZP or CP. However, considering plate-related complications and the incidence of dysphagia after surgery, we preferred ZP for the treatment of single-level CDDD. For multilevel surgery, due to the high subsidence rate of $\mathrm{ZP}$ and with the goal of avoiding subsequent loss of cervical alignment and kyphosis deformity, CP should be preferred without considering the risk of dysphagia.

Our meta-analysis was restricted by some limitations. First, retrospective and nonrandom studies were included in this study, which inevitably gave rise to selection bias. Second, only 10 studies were included, the sample sizes were relatively small, and the follow-up times differed. In addition, a variety of zero-profile devices were used, which could affect the accuracy of our conclusions, although the devices had similar fixation mechanisms and structures. Finally, clinical heterogeneity may have resulted from the various surgical approaches and types of implants used in different research centers.

To the best of our knowledge, this study was the first meta-analysis to compare the subsidence of ZP to that of $\mathrm{CP}$ after ACDF, despite the above shortcomings. Our study showed that ZP had a higher postoperative subsidence than $\mathrm{CP}$, especially in multilevel surgery. Moreover, both devices were safe and effective and achieved similar clinical outcomes. A high-quality, large-sample RCT is required to validate our findings in the future.

Currently, there is no consensus on the relationship between subsidence and clinical effectiveness. The research performed by Lee et al. [18] found that cage subsidence was associated with higher neck and arm VAS scores. Kim et al. [20] also reported that the existence of subsidence was significantly related to unfavorable clinical outcomes at all follow-up assessments, which were evaluated by Odom's criteria. However, Park et al. [32] recruited and divided 77 patients into subsidence and non-subsidence groups, and found that subsidence did not correlate with fusion rate or clinical outcomes. Yson et al. [33] also demonstrated that subsidence did not seem to be predictive of clinical outcomes of ACDF. More longitudinal multicenter RCTs should explore the role of subsidence in clinical prognosis. Furthermore, the surgeon should pay more attention to the deuteropathy of subsidence. We suggest that it is more favorable to use zero-profile implants for one-level surgery and plate fixation in multilevel fusion.

\section{Conclusion}

The ZP, which has been used routinely in recent years, may not reduce the subsidence rate compared to $\mathrm{CP}$. There was no significant difference in subsidence between these two fixed apparatuses after single-level ACDF, while the risk of subsidence in ZP was significantly higher after multilevel fusion. Although there was a high incidence of swallowing discomfort, we would suggest that the anterior plate should be used in multilevel surgery, if possible to reduce subsidence and adverse clinical symptoms in the long term. We conclude that this study provides new opinions for the rational use of ZP.

\section{Abbreviations}

ZP: Zero-profile anchored cage; CP: Cage-plate construct; ACDF: Anterior cervical discectomy and fusion; OR: Odds ratio; Cl: Confidence interval; CDDD: Cervical degenerative disk disease; PRISMA: Preferred Reporting Items for Systematic Reviews and Meta-Analysis; JOA: Japanese Orthopaedic Association; NDI: Neck Disability Index; WMD: Weighted mean difference

\section{Acknowledgements}

Not applicable.

\section{Authors' contributions}

Concept, literature search, and data collection: YJL, YPF, XSZ, and MFG. Statistics, data analysis, and interpretation: YJL, YPF, XS, DDL, and LYZ. Drafting article: YJL and YPF. Critical revision of article: XSZ and MFG. All authors read and approved the final manuscript.

\section{Funding}

No funding.

Availability of data and materials Not applicable. 


\section{Ethics approval and consent to participate}

Not applicable.

\section{Consent for publication}

Not applicable.

\section{Competing interests}

The authors declare that they have no competing interests.

\section{Author details}

'Department of Orthopedic Surgery, The First Affiliated Hospital of Soochow University, 899 Pinghai Road, Suzhou 215000, China. ${ }^{2}$ Department of Orthopedic Surgery, Suzhou Dushuhu Public Hospital (Dushuhu Public Hospital Affiliated to Soochow University), Suzhou, China.

Received: 19 December 2019 Accepted: 13 May 2020 Published online: 24 May 2020

\section{References}

1. Oliver JD, Goncalves S, Kerezoudis P, Alvi MA, Freedman BA, Nassr A, Bydon M. Comparison of outcomes for anterior cervical discectomy and fusion with and without anterior plate fixation: a systematic review and metaanalysis. Spine. 2018;43(7):E413-22. https://doi.org/10.1097/BRS. 0000000000002441.

2. Lee YS, Kim YB, Park SW. Does a zero-profile anchored cage offer additional stabilization as anterior cervical plate? Spine. 2015;40(10):E563-70. https:// doi.org/10.1097/BRS.0000000000000864.

3. Fraser JF, Hartl R. Anterior approaches to fusion of the cervical spine: metaanalysis of fusion rates. Journal of neurosurgery Spine. 2007;6(4):298303. https://doi.org/10.3171/spi.2007.6.4.2.

4. Mobbs RJ, Rao P, Chandran NK. Anterior cervical discectomy and fusion: analysis of surgical outcome with and without plating. Journal of clinical neuroscience : official journal of the Neurosurgical Society of Australasia. 2007;14(7):639-42. https://doi.org/10.1016/j.jocn.2006.04.003.

5. Yang L, Gu Y, Liang L, Gao R, Shi S, Shi J, Yuan W. Stand-alone anchored spacer versus anterior plate for multilevel anterior cervical diskectomy and fusion. Orthopedics. 2012;35(10):e1503-10. https://doi.org/10.3928/ 01477447-20120919-20.

6. Cho SK, Lu Y, Lee DH. Dysphagia following anterior cervical spinal surgery: a systematic review. The bone \& joint journal. 2013;95-B(7):868-73. https://doi. org/10.1302/0301-620X.95B7.31029.

7. Hofstetter CP, Kesavabhotla K, Boockvar JA. Zero-profile anchored spacer reduces rate of dysphagia compared with $A C D F$ with anterior plating Journal of spinal disorders \& techniques. 2015;28(5):E284-90. https://doi.org/ 10.1097/BSD.0b013e31828873ed.

8. Wang ZD, Zhu RF, Yang HL, Gan MF, Zhang SK, Shen MJ, Chen C, Yuan Q. The application of a zero-profile implant in anterior cervical discectomy and fusion. Journal of clinical neuroscience : official journal of the Neurosurgical Society of Australasia. 2014;21(3):462-6. https://doi.org/10.1016/j.jocn.2013. 05.019.

9. Shi S, Liu ZD, Li XF, Qian L, Zhong GB, Chen FJ. Comparison of plate-cage construct and stand-alone anchored spacer in the surgical treatment of three-level cervical spondylotic myelopathy: a preliminary clinical study. The spine journal : official journal of the North American Spine Society. 2015; 15(9):1973-80. https://doi.org/10.1016/j.spinee.2015.04.024.

10. Zhou J, Li J, Lin H, Li X, Zhou X, Dong J. A comparison of a self-locking stand-alone cage and anterior cervical plate for ACDF: minimum 3-year assessment of radiographic and clinical outcomes. Clinical neurology and neurosurgery. 2018;170:73-8. https://doi.org/10.1016/j.clineuro.2018.04.033.

11. Chen Y, Lu G, Wang B, Li L, Kuang L. A comparison of anterior cervical discectomy and fusion (ACDF) using self-locking stand-alone polyetheretherketone (PEEK) cage with ACDF using cage and plate in the treatment of three-level cervical degenerative spondylopathy: a retrospective study with 2-year follow-up. Eur Spine J. 2016;25(7):2255-62. https://doi.org/10.1007/s00586-016-4391-x

12. Nemoto O, Kitada A, Naitou S, Tachibana A, Ito Y, Fujikawa A. Stand-alone anchored cage versus cage with plating for single-level anterior cervical discectomy and fusion: a prospective, randomized, controlled study with a 2-year follow-up. Eur J Orthop Surg Traumatol. 2015;25(Suppl 1):S127-34. https://doi.org/10.1007/s00590-014-1547-4.
13. Li Z, Zhao Y, Tang J, Ren D, Guo J, Wang H, Li L, Hou S. A comparison of a new zero-profile, stand-alone Fidji cervical cage and anterior cervical plate for single and multilevel ACDF: a minimum 2-year follow-up study. European spine journal : official publication of the European Spine Society, the European Spinal Deformity Society, and the European Section of the Cervical Spine Research Society. 2017;26(4):1129-39. https://doi.org/10.1007/ s00586-016-4739-2.

14. Scholz M, Reyes PM, Schleicher P, Sawa AG, Baek S, Kandziora F, Marciano FF, Crawford NR. A new stand-alone cervical anterior interbody fusion device: biomechanical comparison with established anterior cervical fixation devices. Spine. 2009;34(2):156-60. https://doi.org/10.1097/BRS. ob013e31818ff9c4.

15. Clavenna AL, Beutler WJ, Gudipally M, Moldavsky M, Khalil S. The biomechanical stability of a novel spacer with integrated plate in contiguous two-level and three-level ACDF models: an in vitro cadaveric study. The spine journal : official journal of the North American Spine Society. 2012;12(2):157-63. https://doi.org/10.1016/j.spinee.2012.01.011.

16. Qi M, Chen H, Liu Y, Zhang Y, Liang L, Yuan W. The use of a zero-profile device compared with an anterior plate and cage in the treatment of patients with symptomatic cervical spondylosis: a preliminary clinical investigation. The bone \& joint journal. 2013;95-B(4):543-7. https://doi.org/ 10.1302/0301-620X.95B4.30992.

17. Han SY, Kim HW, Lee CY, Kim HR, Park DH. Stand-alone cages for anterior cervical fusion: are there no problems? Korean J Spine. 2016;13(1):13-9. https://doi.org/10.14245/kjs.2016.13.1.13.

18. Lee YS, Kim YB, Park SW. Risk factors for postoperative subsidence of singlelevel anterior cervical discectomy and fusion: the significance of the preoperative cervical alignment. Spine. 2014;39(16):1280-7. https://doi.org/ 10.1097/BRS.0000000000000400.

19. Kast E, Derakhshani S, Bothmann M, Oberle J. Subsidence after anterior cervical inter-body fusion. a randomized prospective clinical trial. Neurosurgical review. 2009;32(2):207-14; discussion 214. https://doi.org/10. 1007/s10143-008-0168-y.

20. Kim SJ, Kim SD. Anterior cervical discectomy and fusion using a double cylindrical cage versus an anterior cervical plating system with iliac crest autografts for the treatment of cervical degenerative disc disease. Journal of Korean Neurosurgical Society. 2014;55(1):12-7. https://doi.org/10.3340/jkns. 2014.55.1.12.

21. Moher D, Liberati A, Tetzlaff J, Altman DG, Group P. Preferred reporting items for systematic reviews and meta-analyses: the PRISMA statement. Int J Surg. 2010;8(5):336-41. https://doi.org/10.1016/j.ijsu.2010.02.007.

22. Phan K, Mobbs RJ. Systematic reviews and meta-analyses in spine surgery, neurosurgery and orthopedics: guidelines for the surgeon scientist. J Spine Surg. 2015;1(1):19-27. https://doi.org/10.3978/j.issn. 2414-469X.2015.06.01.

23. Lu Y, Bao W, Wang Z, Zhou F, Zou J, Jiang W, Yang H, Zhang Z, Zhu X. Comparison of the clinical effects of zero-profile anchored spacer (ROI-C) and conventional cage-plate construct for the treatment of noncontiguous bilevel of cervical degenerative disc disease (CDDD): a minimum 2-year follow-up. Medicine (Baltimore). 2018;97(5):e9808. https://doi.org/10.1097/ MD.0000000000009808.

24. Shin JS, Oh SH, Cho PG. Surgical outcome of a zero-profile device comparing with stand-alone cage and anterior cervical plate with iliac bone graft in the anterior cervical discectomy and fusion. Korean J Spine. 2014; 11(3):169-77. https://doi.org/10.14245/kjs.2014.11.3.169.

25. Yun DJ, Lee SJ, Park SJ, Oh HS, Lee YJ, Oh HM, Lee SH. Use of a zero-profile device for contiguous 2-level anterior cervical diskectomy and fusion: comparison with cage with plate construct. World neurosurgery. 2017;97: 189-98. https://doi.org/10.1016/j.wneu.2016.09.065

26. Zhu D, Zhang D, Liu B, Li C, Zhu J. Can self-locking cages offer the same clinical outcomes as anterior cage-with-plate fixation for 3-level anterior cervical discectomy and fusion (ACDF) in mid-term follow-up? Med Sci Monit. 2019;25:547-57. https://doi.org/10.12659/MSM.911234.

27. Noordhoek I, Koning MT, Jacobs WCH, Vleggeert-Lankamp CLA. Incidence and clinical relevance of cage subsidence in anterior cervical discectomy and fusion: a systematic review. Acta neurochirurgica. 2018;160(4):873-80. https://doi.org/10.1007/s00701-018-3490-3.

28. Kim SY, Yoon SH, Kim D, Oh CH, Oh S. A prospective study with cage-only or cage-with-plate fixation in anterior cervical discectomy and interbody fusion of one and two levels. Journal of Korean Neurosurgical Society. 2017; 60(6):691-700. https://doi.org/10.3340/jkns.2017.0211. 
29. Xiao S, Liang Z, Wei W, Ning J. Zero-profile anchored cage reduces risk of postoperative dysphagia compared with cage with plate fixation after anterior cervical discectomy and fusion. European spine journal : official publication of the European Spine Society, the European Spinal Deformity Society, and the European Section of the Cervical Spine Research Society. 2017;26(4):975-84. https://doi.org/10.1007/s00586-016-4914-5.

30. Nambiar M, Phan K, Cunningham JE, Yang Y, Turner PL, Mobbs R. Locking stand-alone cages versus anterior plate constructs in single-level fusion for degenerative cervical disease: a systematic review and meta-analysis. European spine journal : official publication of the European Spine Society, the European Spinal Deformity Society, and the European Section of the Cervical Spine Research Society. 2017;26(9):2258-66. https://doi.org/10.1007/ s00586-017-5015-9.

31. Tong MJ, Xiang GH, He ZL, Chen DH, Tang Q, Xu HZ, Tian NF. Zero-profile spacer versus cage-plate construct in anterior cervical diskectomy and fusion for multilevel cervical spondylotic myelopathy: systematic review and meta-analysis. World neurosurgery. 2017;104:545-53. https://doi.org/10. 1016/j.wneu.2017.05.045.

32. Park JY, Choi KY, Moon BJ, Hur H, Jang JW, Lee JK. Subsidence after singlelevel anterior cervical fusion with a stand-alone cage. Journal of clinical neuroscience : official journal of the Neurosurgical Society of Australasia. 2016;33:83-8. https://doi.org/10.1016/j.jocn.2016.01.042

33. Yson SC, Sembrano JN, Santos ER. Comparison of allograft and polyetheretherketone (PEEK) cage subsidence rates in anterior cervical discectomy and fusion (ACDF). J Clin Neurosci. 2017;38:118-21. https://doi. org/10.1016/j.jocn.2016.12.037.

\section{Publisher's Note}

Springer Nature remains neutral with regard to jurisdictional claims in published maps and institutional affiliations.

Ready to submit your research? Choose BMC and benefit from:

- fast, convenient online submission

- thorough peer review by experienced researchers in your field

- rapid publication on acceptance

- support for research data, including large and complex data types

- gold Open Access which fosters wider collaboration and increased citations

- maximum visibility for your research: over $100 \mathrm{M}$ website views per year

At $\mathrm{BMC}$, research is always in progress.

Learn more biomedcentral.com/submissions 